\title{
Effect of Variation in Magnesium and Copper on Mechanical Properties of X7475 Aluminium Alloy
}

\author{
L.T. Tuleun', J.D. Amine', K. Abubakar, ${ }^{2, *}$ \\ ${ }^{1}$ Department of Mechanical Engineering, University of Agriculture, Makurdi, Nigeria \\ ${ }^{2}$ Department of Research, Collaboration and Consultancy, National Centre for Technology Management (NACETEM), Abuja, Nigeria \\ *Corresponding author: kz4tawa@gmail.com
}

Received September 12, 2014; Revised September 30, 2014; Accepted October 13, 2014

\begin{abstract}
Aluminium ( $\mathrm{Al}$ ) alloys are employed, from aerospace, automotive body panel, building industry to kitchen wares. This paper attempts to close an existing gap in the usage and variation in the percentage weight (\% w.t.) of two constituents [Magnesium (Mg) and Copper $(\mathrm{Cu})$ ] in $\mathrm{Al}$ alloy and evaluate the impact of such variations on yield strength in $\mathrm{N} / \mathrm{mm}^{2}$ and percentage elongation (\% e) at ambient temperature. Experimental X7475 alloy was prepared from constituents drawn from $6 \% \mathrm{Zn}, 2.5 \%$ - $3.5 \% \mathrm{Mg}, 1.8 \%$ - $3.0 \% \mathrm{Cu}, 0.03$ \% Mn, 0.23 \% $\mathrm{Cr}$ and $\mathrm{Al}$ as balance in all cases. The result revealed that yield strength increased with increase in $\mathrm{Mg}$ and decreased with increase in $\mathrm{Cu}$ as a maximum yield strength of $384.57 \mathrm{~N} / \mathrm{mm}^{2}$ was displayed by an alloy of $2.5 \% \mathrm{Mg}, 3.0 \% \mathrm{Cu}$ while the least yield strength of $130.00 \mathrm{~N} / \mathrm{mm}^{2}$ was recorded by an alloy of $3.5 \% \mathrm{Mg}, 3.0 \%$ Cu. Ductility (\% e) increased with increase in $\mathrm{Cu}$. The paper submitted that mechanical properties of Al alloys depend not only on the content of alloying elements, but also on their relative chemistries with each other, impact of impurities and heat treatments.
\end{abstract}

Keywords: magnesium, copper, mechanical properties, yield strength, elongation, X 7475, aluminium, alloy

Cite This Article: L.T. Tuleun, J.D. Amine, and K. Abubakar, "Effect of Variation in Magnesium and Copper on Mechanical Properties of X7475 Aluminium Alloy.” American Journal of Materials Science and Engineering, vol. 2, no. 4 (2014): 54-61. doi: 10.12691/ajmse-2-4-2.

\section{Introduction}

In all aspect of engineering application, aluminium alloys are employed, ranging from aerospace, automotive body panel, building industry to kitchen wares. The potential for the electronics industry is also obvious. Its desirable chemical, physical and mechanical properties, high strength-to-weight ratio, desirable appearance, nontoxic, non-sparking, non-magnetic, high corrosion resistance, high electrical and thermal conductivities and ease of fabrication [2] makes it a candidate in engineering applications.

Mechanical properties of a material are used to determine its suitability for a particular application [12]. There is the need to develop new and innovative alloys, following [5]; to meet the current and future needs of the aluminium industry; thus necessitated alloying it with other elements especially when workability and processing time is brought to the fore as in plasticity.

The arbitrary yield strength is used for those materials not exhibiting a natural yield point such as nonferrous metals. The percent elongation at failure is the plastic extension of the specimen at failure expressed as change in original gauge length $\mathrm{x} 100$ divided by the original gage length. This extension is the sum of the uniform and no uniform elongations. Any net strain remaining after the stress is released is plastic deformation [12].
Most important elements added to aluminium are; Bismuth (Bi), Chromium (Cr), Copper (Cu), Iron (Fe), Lead (Pb), Magnesium (Mg), Manganese (Mn), Nickel (Ni), Silicon (Si), Titanium (Ti), Zinc (Zn) and Zirconium $(\mathrm{Zr})$. Magnesium is the only frequent addition to aluminium. In some alloys, two or more elements are used in combination (e.g. Magnesium together with Si or Mn). When $\mathrm{Zn}$ is the principal alloying element, such alloy belongs to the $7 \mathrm{xxx}$ series. The alloying elements are added to bring about changes in the properties of aluminium [10].

An X7475 is an experimental alloy, the prefix " $X$ " was factored into the designation to indicate that the alloy is at the experimental stage. When the alloy ceases to be experimental the prefix will be dropped. The first digit (7) indicates the major alloy group, Zinc. Digits two and three (4 and 7) indicate the aluminium purity as 5 was for further identification [10].

[2] conducted an experiment on aluminium alloy of the AA7xxx series, laying emphasis on determining the tensile properties from stress-strain curve within a temperature range of 37 to $325^{\circ} \mathrm{C}$. [15]'s investigation borders on AA5182 solid solution of $\mathrm{Mg}$ in $\mathrm{Al}$, with alloying elements drawn from $\mathrm{Al}-5.0 \% \mathrm{Mg}-0.3 \% \mathrm{Mn}-$ $0.1 \% \mathrm{Cu}-0.2 \% \mathrm{Si}-0.2 \% \mathrm{Fe}$ (w.t. \%), varying only the thickness of the sheet from 1.5 to $2.0 \mathrm{~mm}$, while all other elements were held constant.

This paper attempts to close an existing gap in the usage and variation in percentage weight (\% w.t.) of two 
constituents; Magnesium and Copper, in aluminium alloy and evaluate the effect of such variations on yield strength and percentage elongation (\% e) at ambient temperature. In this work, we refer to an alloy of $6 \% \mathrm{Zn}, 3.5 \% \mathrm{Mg}$, $3.0 \% \mathrm{Cu}, 0.03 \% \mathrm{Mn}, 0.23 \% \mathrm{Cr}$ and $\mathrm{Al}$ balance as an alloy of $3.5 \% \mathrm{Mg}, 3.0 \% \mathrm{Cu}$ for ease of presentation and to indicate that emphasis is on these elements, since $\mathrm{Al}$ will always balance the weight and other constituents were assumed constant.

Section 1 is a brief overview of the basis for this experimental and developmental research, section 2 discussed materials and experimental procedures, section 3 discussed the result of experiments and in section 4, we concluded on the premise of the experiment.

\section{Materials and Experimental}

\subsection{Materials}

Materials used for this experiment include commercially available aluminum of $99.9 \%$ purity in the form of bundles of wires, $99.5 \%$ pure zinc and $99.5 \%$ pure cupper in precipitate form, magnesium ligands, Ferro-Chromium (Fe-Cr), Ferro-Manganese (Fe-Mn), and sulphur.

\subsection{Experimental Procedure}

A permanent mould was designed to produce standard samples of X7475 alloy measuring $5 \mathrm{~mm}$ gauge diameter and $30 \mathrm{~mm}$ gauge length. Percentage weight of $\mathrm{Mg}$ and $\mathrm{Cu}$ were varied from $2.5 \%-3.5 \%$ and $1.8 \%-3.0 \%$, while $\mathrm{Mn}, \mathrm{Cr}$, and $\mathrm{Zn}$ are kept constant as aluminium completes the mixture in all cases. Table 1 shows the alloy configurations adopted for this experiment.

Table 1. PERCENTAGE WEIGHT OF CONSTITUENTS SHOWING VARIATION IN MG AND CU

\begin{tabular}{|c|c|c|c|c|c|c|c|}
\hline \multirow{2}{*}{ S/N } & \multirow{2}{*}{ Constituent } & \multicolumn{7}{|c|}{ Percentage (\% w.t)/ Weight(g) } \\
\cline { 3 - 8 } & & $\%$ & $\mathrm{~g}$ & $\%$ & $\mathrm{~g}$ & $\%$ & $\mathrm{~g}$ \\
\hline 1 & $\mathrm{Zn}$ & 6.00 & 24.00 & 6.00 & 24.00 & 6.00 & 24.00 \\
\hline 2 & $\mathrm{Cr}$ & 0.23 & 0.20 & 0.23 & 0.20 & 0.23 & 0.20 \\
\hline 3 & $\mathrm{Mn}$ & 0.03 & 0.12 & 0.03 & 0.12 & 0.03 & 0.12 \\
\hline 4 & $\mathrm{Mg}$ & 2.50 & 10.00 & 3.00 & 12.00 & 3.50 & 14.00 \\
\hline 5 & $\mathrm{Cu}$ & 1.80 & 7.20 & 2.50 & 10.00 & 3.00 & 12.00 \\
\hline 6 & $\mathrm{Al}$ & \multicolumn{7}{|c|}{ Balance } \\
\hline
\end{tabular}

\subsubsection{Preparation of Test Samples}

A table top portable digital weighing machine was used in measuring the alloy constituents. Al existed in wire forms and was cut to smaller pieces for effective melting and ease of measurement. Zn existed in granular form having about $99.5 \%$ purity. Magnesium ligands (an amalgam of $\mathrm{Al}$ and $\mathrm{Mg}$ to make $\mathrm{Mg}$ stable) were in lump form, Copper was in powder and Ferro- chromium an alloy of $23 \% \mathrm{Fe}$ and $77 \% \mathrm{Cr}$ in granular. Additional 0.1 grams of Sulphur was used to eradicate the Fe contained in $\mathrm{Cr}$ and Mn respectively. Fe-Mn; 20 \% Fe and $80 \%$ Mn improves the workability of the alloy.

To produce samples, $3600 \mathrm{~g}$ of alloy was required; an additional $400 \mathrm{~g}$ was added to take care of casting risers, gate and tolerance against wastes.

The crucible was placed in the furnace to preheat it to a temperature of $200^{\circ} \mathrm{C}$ hence eradicating the moisture content. Melting temperature was alternated between 450 $1100^{\circ} \mathrm{C}$, taking care of preheat, heat requirement to melt all constituents and that required for proper homogenization of the alloy mixture. Constituents were charged in according to melting point temperature and order of quantity to facilitate homogenization; introducing $\mathrm{Al}, \mathrm{Zn}, \mathrm{Mg}, \mathrm{Cu}, \mathrm{Mn}, \mathrm{Cr}$ and S. A pipe was used as guide to prevent $\mathrm{Mg}$ from getting in contact with the atmospheric oxygen since it readily reacts and flammable.

A mould designed to take 1200 g per charge was used in rolling out three (3) samples at a pour.

\subsubsection{Constituent Analysis, Metallography and Tensile Test}

Multisampling bench top XRF Analyser, X-Supreme 8000 , was used to perform semi and full quantitative analysis of samples. Turker solution etching chemical was used to cleanse the surface of samples cut for microstructure/ metallographic investigations. Standard samples prepared to fit into the jaws of Universal Tensile Strength Testing machine: BS EN ISO 13934 were used for tensile strength test. With load in $\mathrm{KgF}$, percentage elongation, yield strength and strain in response to variation in load were computed.

\section{Result and Discussion}

\subsection{Discussion of Result on Constituent Analysis}

By design, the alloy produced was made of constituents drawn from 6\% $\mathrm{Zn}, 2.5 \%-3.5 \% \mathrm{Mg}, 1.8 \%-3.0 \% \mathrm{Cu}$, $0.03 \% \mathrm{Mn}, 0.23 \% \mathrm{Cr}$ and $\mathrm{Al}$ as balance in all cases. However, $0.1 \mathrm{~g}$ of $\mathrm{S}$ which doubled as quantity of $\mathrm{Fe}$ in $\mathrm{Cr}$ and $\mathrm{Mn}$ was added to eradicate Fe. The purpose of conducting the material composition test was to establish if the constituents claimed to be in the alloy were present in the acclaimed quantity. The result of composition as presented on Table 2 revealed presence of elements like Potassium, Silicon and Titanium, which were not added by design. These were in the form of impurities. We observed that they may not be unconnected with the melting carried out on a local furnace when there was power outage and during pouring process. It can also be much linked to particles picked up from Fe-Cr or Fe-Mn as was established in alloys produced by [1], especially when casting is involved. The impacts of these elements on mechanical properties vary from increase in hardness to decrease in tensile strength.

The percentage by weight of Sodium $(\mathrm{Na})$ varied between 1.951 in sample 1 to 2.179 in sample 9 as represented on Table 2 . This variation is strongly linked to the change in quantity of other constituents of the alloy. For instance, in sample 2, Na has $2.064 \%$ wt. in contrast to the original design where Na was not part of the alloy. By implication, since $\mathrm{Al}-\mathrm{Cl}$ can be reduced with $\mathrm{Na}$ and reacts with $\mathrm{Si}$ and other Oxides to form oxide solution at temperature up to $240^{\circ} \mathrm{C}$ [3], then Na may be present.

In sample 3, 4, 5 and 6, Na presence are 2.046, 1.991, 1.990 and 2.149 respectively. From the tensile strength result, it can be deduced that \% wt. of $\mathrm{Na}$ has no stable pattern on the tensile strength of the alloy in question. 
Table 2. PERCENTAGE WEIGHT OF CONSTITUENTS AS REVEALED BY XRF ANALYSER (X-SUPREME 8000)

\begin{tabular}{|c|c|c|c|c|c|c|c|c|c|c|}
\hline \multirow{13}{*}{ 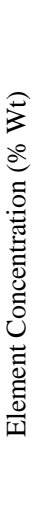 } & & 1 & 2 & 3 & 4 & 5 & 6 & 7 & 8 & 9 \\
\hline & $\mathrm{Na}$ & 1.951 & 2.064 & 2.046 & 1.991 & 1.990 & 2.149 & 2.102 & 2.163 & 2.179 \\
\hline & $\mathrm{Mg}$ & 2.534 & 3.031 & 2.327 & 3.240 & 3.002 & 3.672 & 3.312 & 2.198 & 3.567 \\
\hline & $\mathrm{Al}$ & 89.937 & 89.491 & 89.389 & 89.157 & 88.763 & 88.391 & 88.444 & 88.314 & 88.260 \\
\hline & $\mathrm{Si}$ & 2.600 & 2.204 & 2.850 & 2.535 & 2.931 & 2.266 & 2.942 & 2.703 & 2.573 \\
\hline & $S$ & 0.103 & 0.092 & 0.081 & 0.094 & 0.098 & 0.105 & 0.099 & 0.128 & 0.113 \\
\hline & $\mathrm{K}$ & 0.008 & 0.006 & 0.009 & 0.006 & 0.007 & 0.006 & 0.007 & 0.007 & 0.007 \\
\hline & $\mathrm{Ca}$ & 0.006 & 0.000 & 0.011 & 0.000 & 0.007 & 0.000 & 0.006 & 0.007 & 0.009 \\
\hline & $\mathrm{Ti}$ & 0.003 & 0.002 & 0.014 & 0.004 & 0.006 & 0.006 & 0.007 & 0.010 & 0.004 \\
\hline & $\mathrm{Cr}$ & 0.017 & 0.016 & 0.009 & 0.010 & 0.022 & 0.009 & 0.014 & 0.009 & 0.020 \\
\hline & $\mathrm{Mn}$ & 0.005 & 0.009 & 0.007 & 0.009 & 0.013 & 0.014 & 0.009 & 0.011 & 0.011 \\
\hline & $\mathrm{Fe}$ & 0.078 & 0.162 & 0.162 & 0.122 & 0.200 & 0.315 & 0.219 & 0.148 & 0.144 \\
\hline & $\mathrm{Zn}$ & 2.758 & 2.924 & 2.924 & 2.831 & 2.960 & 2.966 & 2.838 & 3.303 & 3.112 \\
\hline
\end{tabular}

The concentration in \% wt. of Mg observed an upward and downward change from sample 1 through 9. A maximum \% wt. of 3.672 can be observed in sample 6 . In another development, a least \% wt. of 2.327 was recorded in sample 3. This negated the measured quantity of $2.5 \%$ wt. in samples 1, 2 and 3. The result of composition also revealed a variation in the $\mathrm{Mg}$ concentration in samples 4 , 5 and 6 which were chosen to be $3.0 \%$ wt. by design but revealed to be 3.24, 3.002 and $3.672 \%$ wt. respectively as presented on Table 2 . This variation may be due to human error in measurement. More so, when the quantity measured was small. The impact of $\mathrm{Mg}$ on mechanical properties of the alloy is noticeable in the area of increase in tensile strength, with less impact on elongation.

Notable in the composition analysis also was Silicon (Si). Its \% wt. ranges from $2.204-2.942$. In sample 1 , $2.6 \%$ Wt. concentration was revealed, the highest was recorded in sample 5 . The presence of Si can be linked to $\mathrm{Fe}, \mathrm{Cr}$ and $\mathrm{Mn}$ which were in Fe-Cr and Fe-Mn even as impurities picked up during casting. The impact of Si is to give good casting characteristics to the alloy, following [13]. Though, efforts were made to reduce the content of unwanted constituents by using permanent mould for the casting and placing all constituents on impurity free surfaces before melting; these had little impact, but not to the extent of eradicating Si completely. Again Al- Cu was an amalgam; there is also likelihood of picking up some Si.

Sulphur (S), was added to the alloy owing to its ability to eradicate $\mathrm{Fe}$ in $\mathrm{Fe}-\mathrm{Cr}$ and $\mathrm{Fe}-\mathrm{Mn}$, it can also increase the corrosion-resistant inherent in aluminium, following [12]. By measurement, $0.1 \%$ wt. concentration was added. The result as presented on Table 2 revealed a highest value of $0.128 \%$ wt. recorded in sample 8 with a least value of $0.081 \%$ wt. in sample 3 . It can be observed that the \% wt. of S and that of Fe in all the samples are not equal. For instance, in sample 7, S had $0.099 \%$ wt. presence while $\mathrm{Fe}$ has $0.219 \%$ wt., such variation recorded may be linked to human error on one hand. On another hand, the presence of $\mathrm{Fe}$ in ligands was never established beforehand. The analysis prior to melting samples revealed an expected $0.1 \%$ wt. of Fe contributed by Fe-Cu and Fe-Mn. This prompted the addition of $0.1 \%$ wt. of S.

Elements such as Potassium (K), Calcium (Ca) and Titanium (Ti) were not added by design to the alloy. Though they appear in traces, as impurities, but their impact on the mechanical properties of the alloy cannot be neglected. In the case of K, ranging from $0.006-0.009 \%$ wt. it constitutes one of those elements which are not frequently added to $\mathrm{Al}$ as it was first isolated by Hans
Christian Oersted (1777-1851) in 1824 by reducing it from its oxide with potassium amalgam as in [3]. Notable on Table 2 also is the nature of fluctuations experienced in \% wt. of Ca where 0 was recorded in samples 2, 4 and 6 respectively. Samples 1 and 7 pulled $0.006 \%$ wt. each while samples 5 and 8 recorded $0.007 \%$ w.t. each. Ca has very low solubility in $\mathrm{Al}$ and forms the intermetallic $\mathrm{CaAl}_{4}$. Ca also combines with $\mathrm{Si}$ to form $\mathrm{CaSi}_{2}$, which is almost insoluble in $\mathrm{Al}$ and therefore will decrease age hardening. Its effect on aluminum-silicon alloys is to increase strength and decrease elongation, but it does not make these alloys heat treatable.

The \% wt. of Ti ranges from the least \% wt. of 0.002 to 0.014 as recorded on Table 2 . Sample 2 has the least value while sample 3 has the maximum value. $\mathrm{Cr}$ has been observed to have high corrosion resistance and hardness. Its presence in this alloy is to improve on the hardness and corrosion resistance of the alloy as a measure of the ability of the alloy to withstand sudden load and serve in corrosive environment. By implication, sample 3, 6 and 8 recording $0.009 \%$ wt. of $\mathrm{Cr}$ each are expected to have lower corrosion resistivity when compared with alloy samples 1, 5 and 9 with $0.017,0.022$ and $0.02 \%$ wt. The structure revealed that sample 5 may be harder and resist corrosion better than sample 3 .

Mn was to make the alloy harder, without making it any more brittle and $\mathrm{Zn}$ was to induce some strength in the alloy as required by the 7xxx series of superplastic alloys. Samples 2, 4 and 7 all recorded \% wt. of 0.009 each of Mn and may be harder than samples 3 and 1 each having 0.007 and 0.005 , if this assertion is to hold. Sample 6 has the highest \% wt. of $\mathrm{Mn}$. If this can be converted to effective mechanical property, then this alloy should perform better in hardness environment. On the other hand, sample 1 may perform less.

The presence of Fe was as a result of the drop out from the addition of Fe-Cr and Fe- Mn. Material composition analysis has revealed that Fe was not eradicated even at the addition of S. Similarly, if its impact on the mechanical property of the alloy is to be irrelevant, then the \% wt. of S and Fe should balance off. Contrariwise, for instance sample 1 contains $0.103 \%$ wt. of S and $0.078 \%$ wt. of Fe. This scenario is repeated all through samples. The implication of this result is that Fe may be responsible for the brittleness nature of some of the samples even before tensile test was conducted and may even cause necking and reduce the tensile strength.

Zinc (Zn) was measured to be $6.00 \%$ w.t. a quantity maintained throughout all samples using the electronic weighing machine. On the contrary, the result presents a 
challenge of establishing alloy composition materials beyond reasonable doubt hitherto casting. The maximum \% wt. as analyzed on Table 2 is sample 8 with $3.30 \%$ wt. concentration. The X7475 class of alloy is governed by \% wt. of $\mathrm{Zn}$. The least \% wt. of 2.758 was recorded in sample 1 . Zn contributes to only solid solution strengthening of the alloy [14]. The impact of $\mathrm{Zn}$ on mechanical properties has been investigated by [1] to be increase in tensile strength in combination with $\mathrm{Mg}$.

\subsection{Effect of Variation in $\mathrm{Mg}$ and $\mathrm{Cu}$ on Tensile Strength and Microstructure of Aluminium Alloy}

Often, stress and strain are defined on the basis of a simple uniaxial tension test. Tensile tests are performed for several reasons. The results of tensile tests are used in selecting materials for engineering applications. Tensile properties frequently are included in material specifications to ensure quality. These properties often are measured during development of new materials and processes, so that different materials and processes can be compared. Finally, tensile properties often are used to predict the behavior of a material under forms of loading other than uniaxial tension $([4,6])$. During tensile testing of a material sample, the stress-strain curve is a graphical representation of the relationship between stress, derived from measuring the load applied on the sample, and strain, derived from measuring the deformation of the sample, i.e. elongation, compression, or distortion [9].
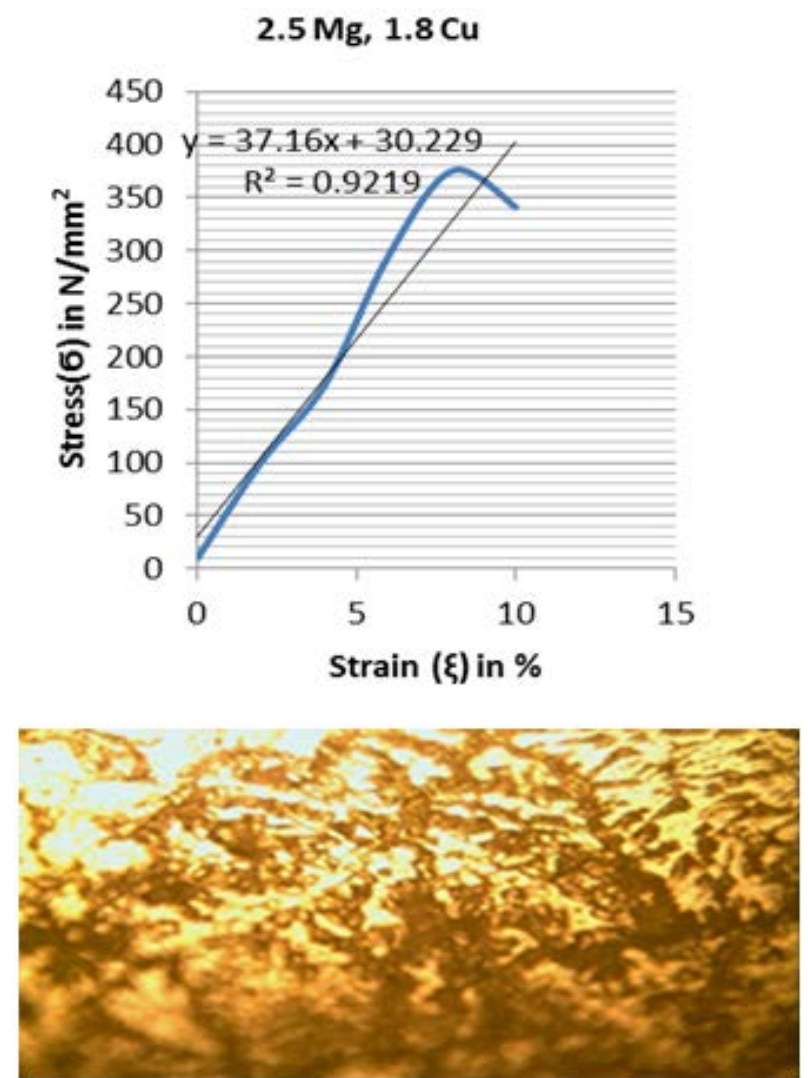

Figure 1. Stress- Strain curve and micro structure of $2.5 \mathrm{Mg}, 1.8 \mathrm{Cu}$ alloy

The micrograph of an alloy with $89.41 \% \mathrm{Al}, 6 \% \mathrm{Zn}$, $2.5 \% \mathrm{Mg}, 1.8 \% \mathrm{Cu}, 0.03 \% \mathrm{Mn}$ and $0.23 \% \mathrm{Cr}$ formation which was heat treated to half melting point temperature is shown in Figure 1 above. The structure revealed a matrix dominated by $\mathrm{Al}$ but surrounded by $\mathrm{Zn}$ and other constituents dispersed all through the alloy. The grains were relatively dislocation free compared with the grain boundaries where extrinsic grain boundary dislocations were regularly arranged into arrays. The formation of these arrays is a function of the heat treatment given to the alloy that improved on the binding energy between the latex of the alloy.

This alloy also has a maximum elongation of $26 \%$ at a strain rate of $0.26 \mathrm{~mm}$ and yield strength of $370.05 \mathrm{~N} / \mathrm{mm}^{2}$. Presented above also is the stress/ strain curve with a linear function of the form $y=37.16 x+30.229$ $R^{2}=0.9219$. Where $\mathrm{y}$ represent the yield strength and $\mathrm{x}$ apparently representing the strain rate of the alloy. $\mathrm{R}^{2}$ is a measure of correlation between the measured strength before final deformation of the alloy. Since $\mathrm{R}^{2}$ is greater than 0.80 , it is an indication of close relationship between the datum points. The implication of this function and curve is that any variation in content of $\mathrm{Mg}$ and/or $\mathrm{Cu}$ may have a positive impact on the tensile strength of the alloy. Though the microstructure depicts closed matrix in the lattice, yet there are some failure sites within which the alloy is most likely to fail. This alloy failed at yield strength of $375.346 \mathrm{~N} / \mathrm{mm}^{2}$.
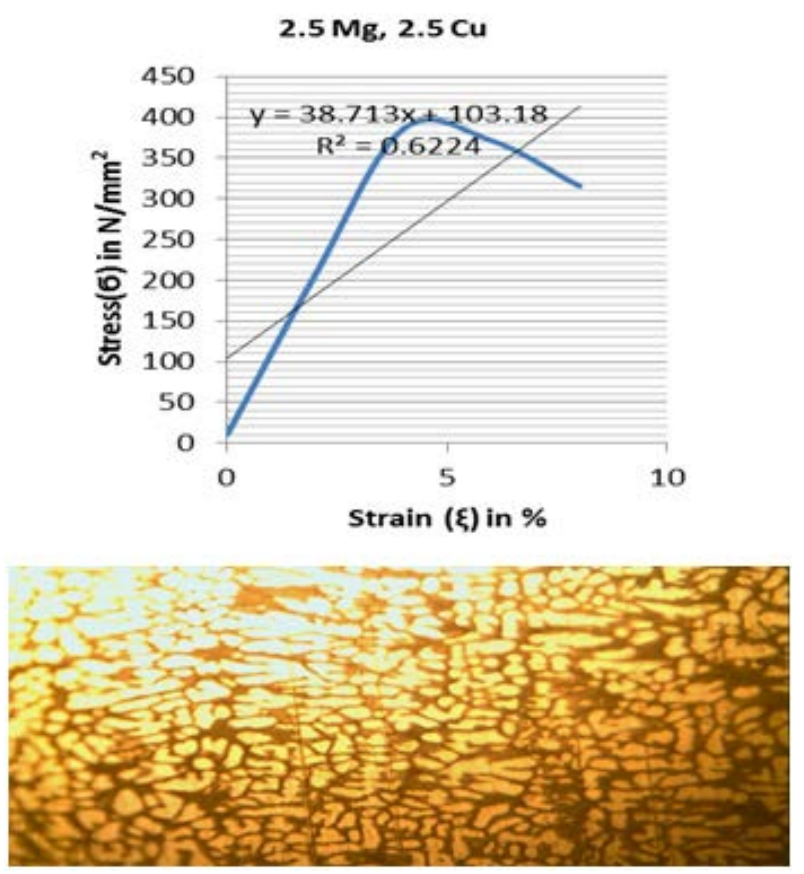

Figure 2. Stress- Strain curve and micro structure of 2.5 Mg, 2.5 Cu alloy

Apparently, an equal \% wt. of $\mathrm{Mg}$ and Cu may produce a stress/strain curve that is almost linear in nature as the sample maintained a lengthy uniform shape before necking occurred. This may be ascribed to the equality in $\mathrm{Mg}$ and $\mathrm{Cu}$ content. The property of the curve presented in Figure 2 above is characterized by a function of the form $y$ $=38.713 x+103.18, R^{2}=0.6224$. With $R^{2}=0.6224$, there is correlation between the yield point strength and other stress points; this may explain the closeness of the stress against strain. Yield strength of $385.80 \mathrm{~N} / \mathrm{mm}^{2}$ was recoded against strain of $23 \%$ elongation. Again, at $260.85 \mathrm{~N} / \mathrm{mm}^{2}$, the alloy demonstrated an initial failure signal, albeit elongated far beyond the point with subsequent test. By observation, the stress-strain curve was almost linear in nature.

Since the plastic behaviour of $\mathrm{Al}$ alloy is influenced by $\alpha$-Al phase and eutectic $\mathrm{Mg}$ particles, it is reasonable to 
expect that the Ultimate Tensile Strength (UTS) and the elongation to fracture are controlled by a combined effect of $\mathrm{Mg}$ and $\mathrm{Cu}$ and eutectic $\mathrm{Zn}$ features in the alloy. The micrograph also revealed a well-coordinated lattice following the uniformity in the shape depicting a smectic arrangement. On another hand, there exist porous sites that may serve as potential failure sites and may be responsible for the failure of the alloy.
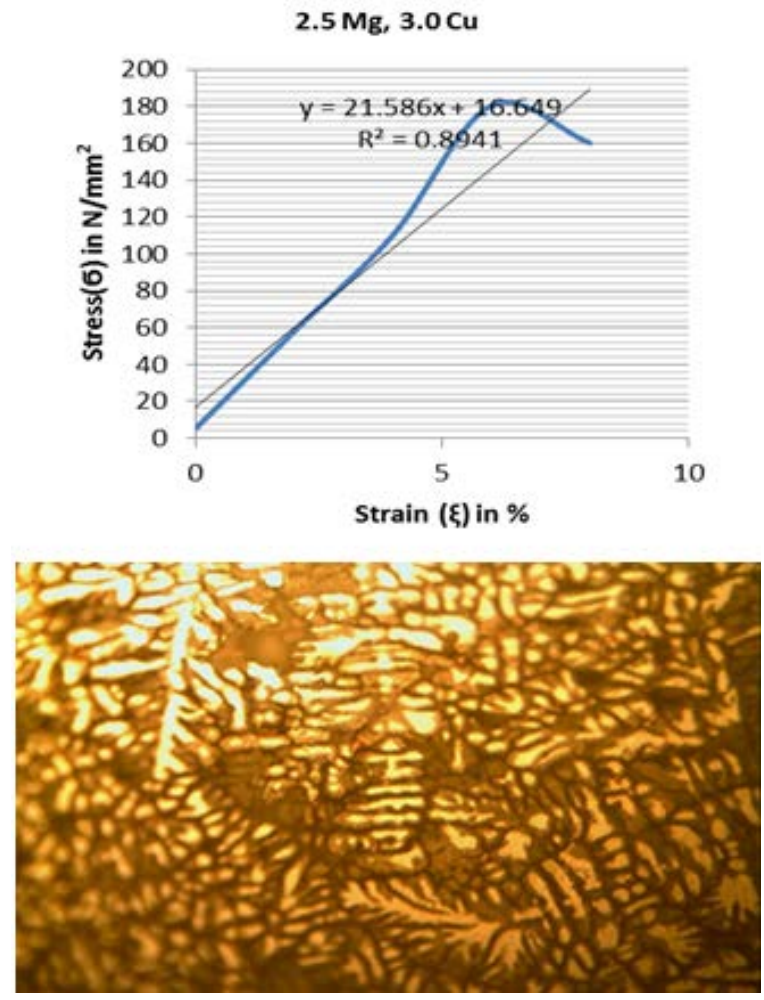

Figure 3. Stress- Strain curve and micro structure of $2.5 \mathrm{Mg}$, 3.0 Cu alloy

The sample represented on Figure 3 is an alloy of $6 \%$ $\mathrm{Zn}, 2.5 \% \mathrm{Mg}, 3.0 \% \mathrm{Cu}, 0.03 \% \mathrm{Mn}, 0.23 \% \mathrm{Cr}$ and $\mathrm{Al}$ as balance. As cast, the microstructure of the alloy depicts a convergence of aligned particles clustered towards the nucleus of the alloy with lots of failure initiating sites emerging from the centre. These sites are represented by lines cutting through the entire surface of the alloy.

The stress-strain curve had an Ultimate Tensile Strength (UTS) of $180.59 \mathrm{~N} / \mathrm{mm}^{2}$, and then decreased to $160.28 \mathrm{~N} / \mathrm{mm}^{2}$ at failure. This fall short compared to the previous alloy. It may be safe to assume that increase in \% wt. of $\mathrm{Cu}$ was responsible for this drop in UTS. The relationship of the curve can be linked with the function $y$ $=21.586 x+16.649$ and $R^{2}=0.8941$. The implication of this function on the UTS of the alloy is that of a positive correlation between the $\mathrm{Mg}$ and $\mathrm{Cu}$ content. However, if heat-treated, an increase in tensile strength may be recorded.

Figure 4 represent the Stress/Strain curve and micro structure of $3.0 \mathrm{Mg}, 1.8 \mathrm{Cu}$ alloy. It can be revealed from the micrograph that its particles are clustered within the lattice. The impact of heat treatment may be responsible for the closure of the streaks noticed in the structure. The variations made in the percentage of $\mathrm{Cu}$ and $\mathrm{Mg}$ reflects on the mechanical properties of the alloy. An equation of the form $y=18.372 x+58.457$ represent the linear function and has a correlation function less than $0.8 ; R^{2}=0.769$. This alloy has $18.33 \%$ elongation and maximum strain of 0.18 . The rate of elongation is a function of the structure and alloy composition following [4]. A comparison of this alloy and that with equal \% wt. of $\mathrm{Mg}$ and $\mathrm{Cu}$ revealed higher strength has been demonstrated in that alloy with equal $\mathrm{Mg}$ and $\mathrm{Cu}$ representation. This result points to the fact that even as $\mathrm{Mg}$ improves on hardness of $\mathrm{Al}$, it may improve on the tensile strength too. An innovative combination of $\mathrm{Mg}$ and $\mathrm{Cu}$ is important to achieve this.
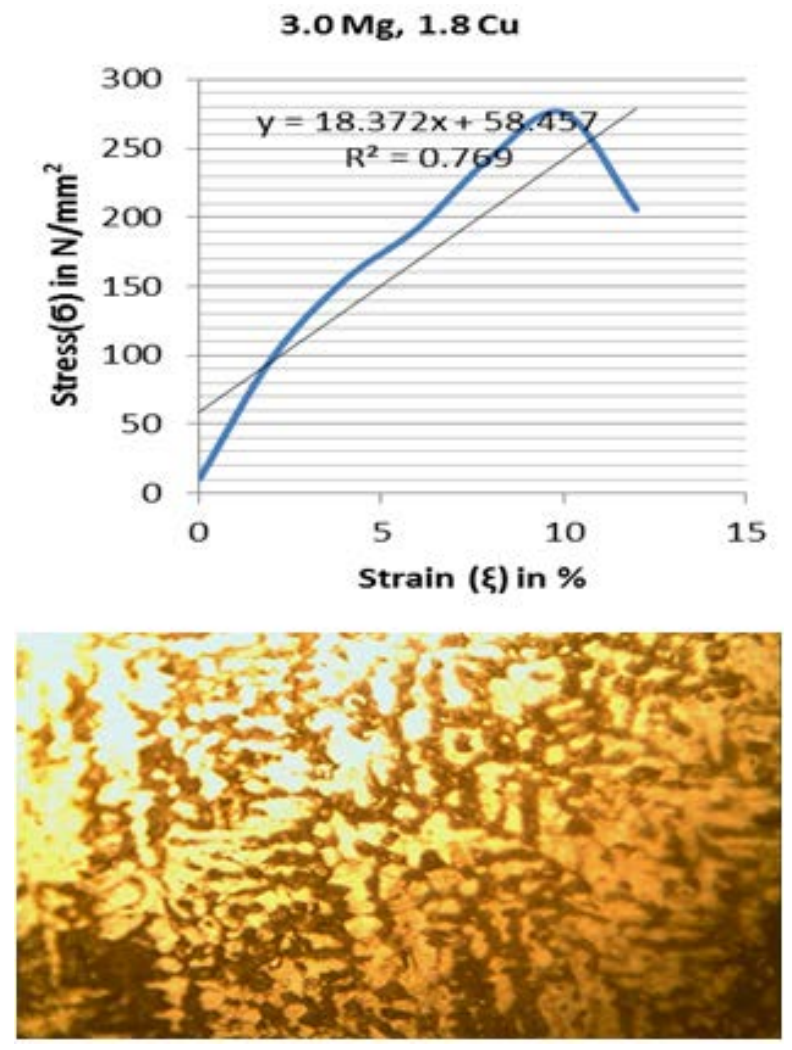

Figure 4. Stress- Strain curve and micro structure of 3.0 Mg, 1.8 Cu alloy

$3.0 \mathrm{Mg}, 2.5 \mathrm{Cu}$
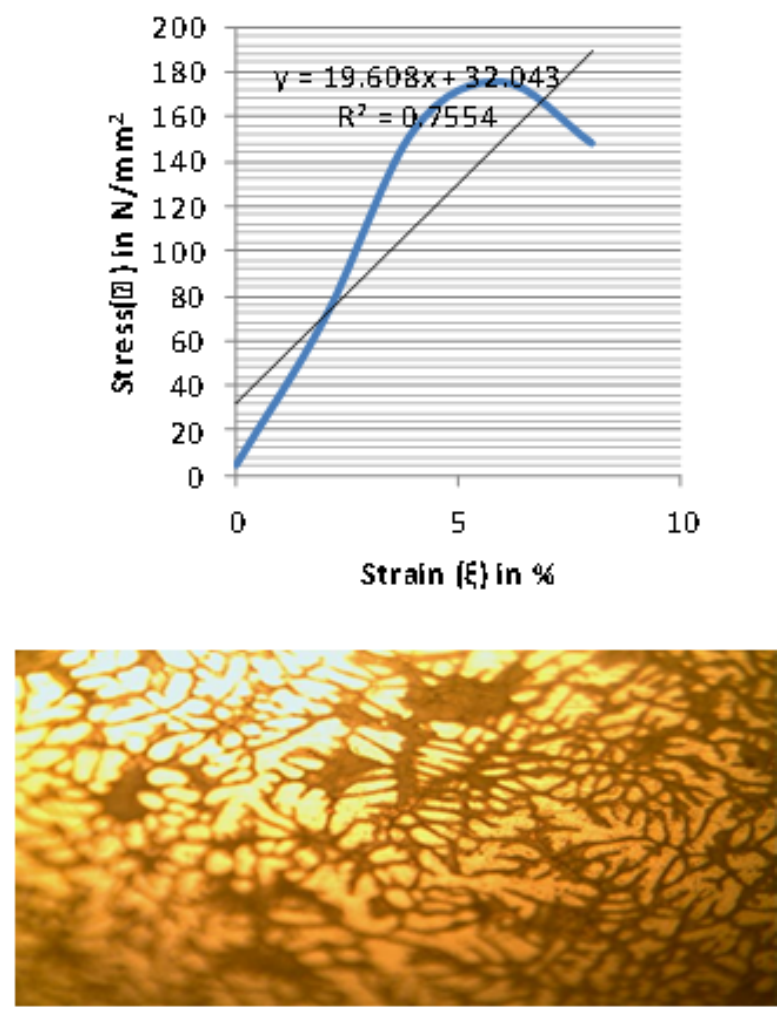

Figure 5. Stress- Strain curve and micro structure of 3.0 Mg, 2.5 Cu alloy 
Segregation flocks were detected in the interface between $\mathrm{Al}$ and other constituents of the alloy, as shown in Figure 5 above. The formation of segregation bands is due to the local collapse of the dendrite network that causes flow of enriched liquid during the solidification phase. The main factors affecting this mechanism are the heat transfer coefficient, the interior flow velocity and the reduced solidification rate. Thus, the increased solidification time promotes the collapse of $\alpha$-Al dendrites and, in turn, the formation of segregation.

Apparently, the gradient of the linear function and correlation varies with respect to the yield strength of the alloy. This can be observed when Figure 4 and Figure 5 are juxtaposed. The function $y=19.608 x+32.043$ with $R^{2}=0.7554$ has a gradient of 19.608 which surpass that alloy with $3.0 \%$ wt. Mg and $1.8 \%$ wt. Cu configuration. This alloy displayed a structure with less purloins in the lattice. The matrix also portrayed higher percentage of aluminium spread all over the lattice. At the point of material linearity, geometric linearity and deformation also occurred following [7]. The heterogeneous nature of the alloy is responsible for the variation in the mechanical (tensile strength) properties and yield strength of $175.44 \mathrm{~N} / \mathrm{mm}^{2}$.

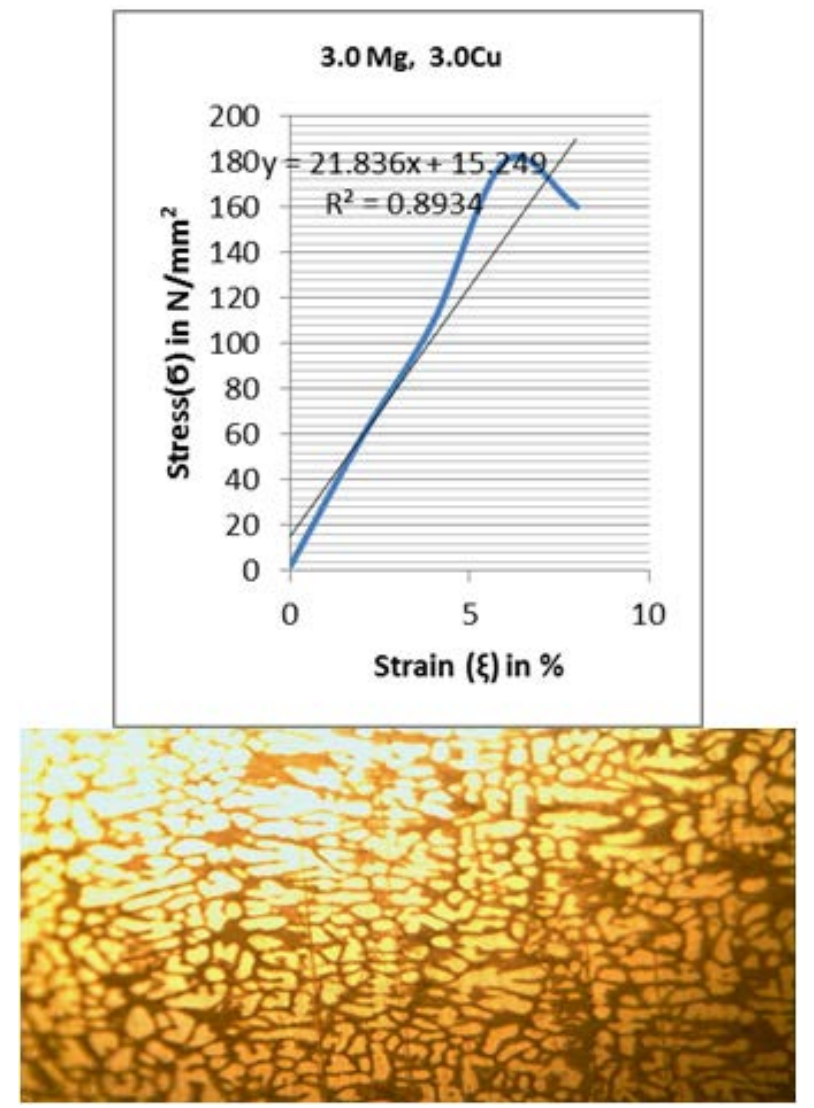

Figure 6. Stress- Strain curve and micro structure of $3.0 \mathrm{Mg}$, 3.0 Cu alloy

On the other hand, the 3.0 Mg, 3.0 Cu alloy shows a finer microstructure and defects free structure due to the higher pouring speed during the casting process and faster solidification rate. A similar trend follows from the alloy of $2.5 \% \mathrm{Mg}$ and $2.5 \% \mathrm{Cu}$. It may be safe to observe that alloys with equal \% wt. of $\mathrm{Mg}$ and $\mathrm{Cu}$ have finer structures and may be less porous to failure, Figure 6 refers please.

Figure 7 represent the stress/strain curve and micro structure of $3.5 \mathrm{Mg}, 1.8 \mathrm{Cu}$ alloy configuration. The linear function, $y=10.863 x+25.284$ and $R^{2}=0.6457$ is $a$ demonstration of the intimacy of this alloy to the Hookean stress-strain behavior to a larger extent compared to the previous alloys. They both ceased to obey the linearity at points where stress equals $130 \mathrm{~N} / \mathrm{mm}^{2}$. This result upheld the fact established in [2]. The implication of this result on mechanical properties of the alloy is that this alloy may sustain a uniaxial load within a capacity of $130 \mathrm{~N} / \mathrm{mm}^{2}$. Apparently, an increase in the \% wt. of $\mathrm{Mg}$ increased the yield strength of the alloy.

\section{$3.5 \mathrm{Mg}, 1.8 \mathrm{Ou}$}
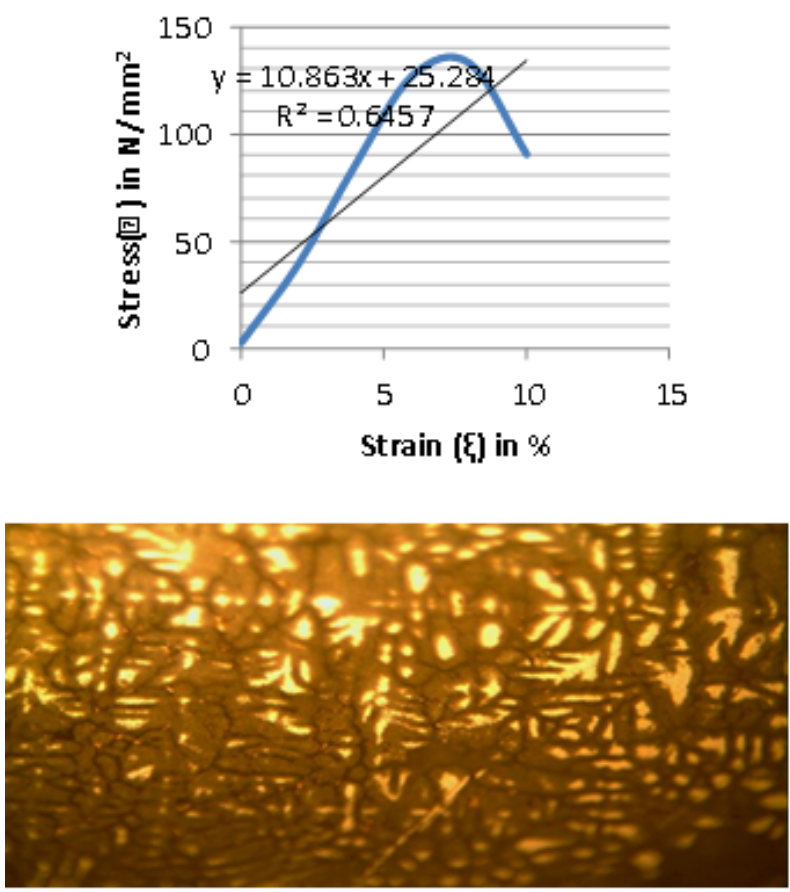

Figure 7. Stress- Strain curve and micro structure of $3.5 \mathrm{Mg}, 1.8 \mathrm{Cu}$ alloy

\section{$3.5 \mathrm{Mg}, 2.5 \mathrm{Cu}$}
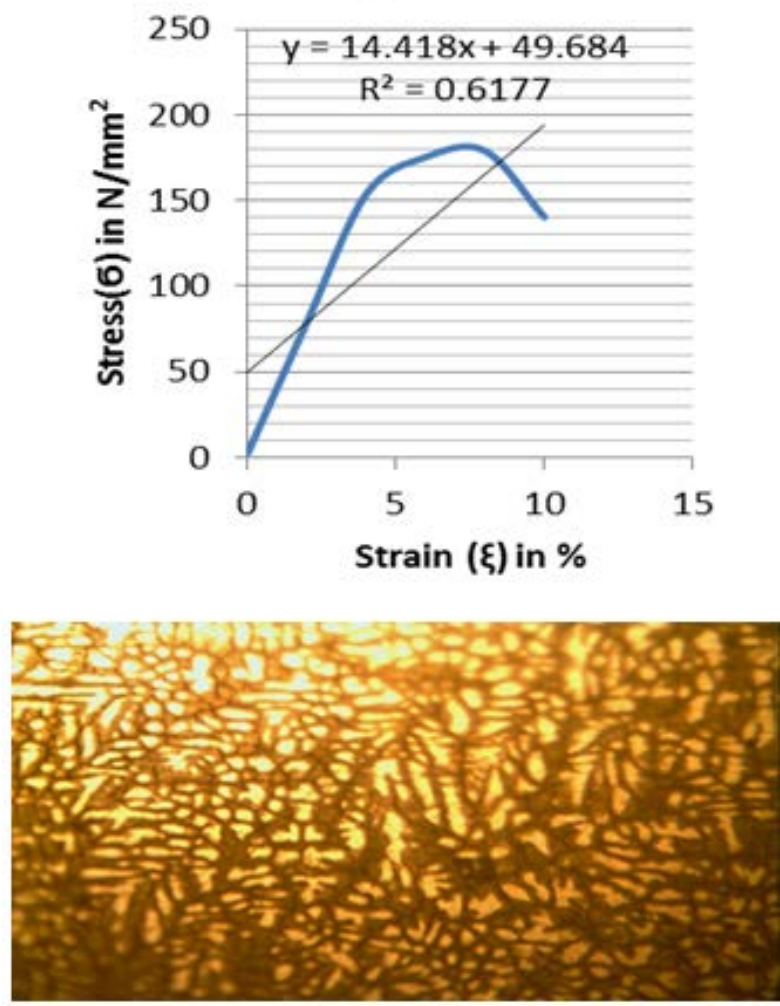

Figure 8. Stress- Strain curve and micro structure of 3.5 Mg, 2.5 Cu alloy 


\section{$3.5 \mathrm{Mg}, 3.0 \mathrm{Cu}$}
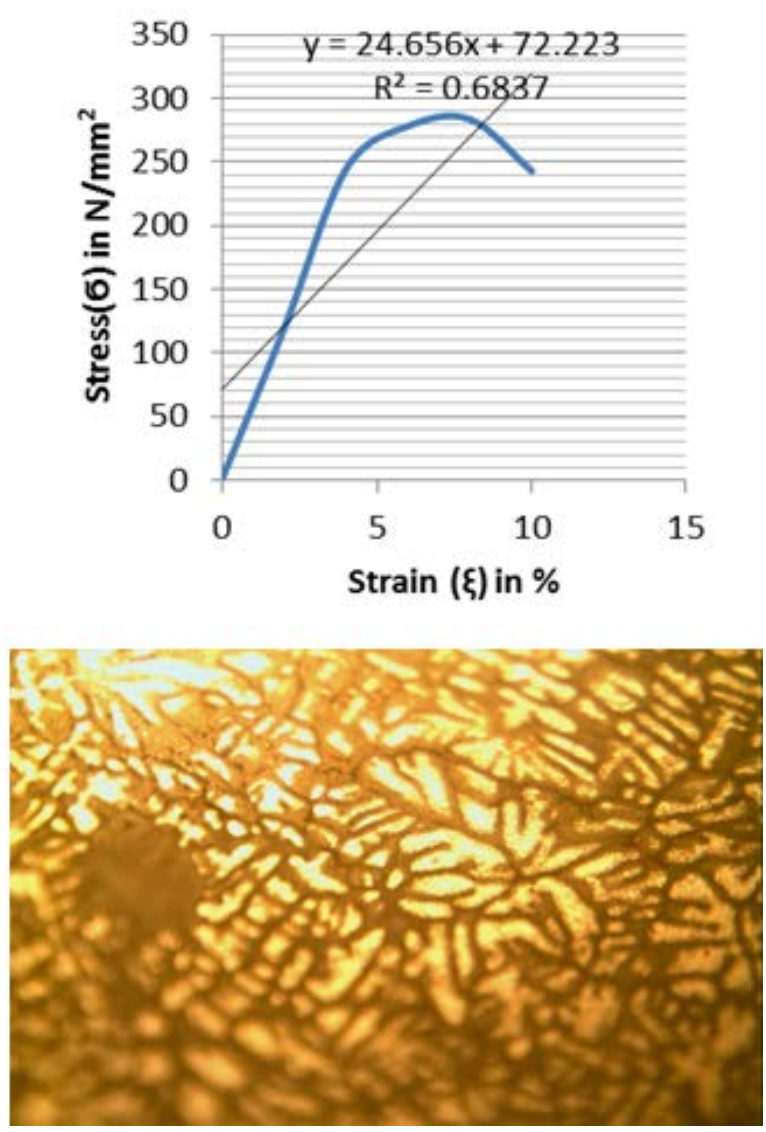

Figure 9. Stress- Strain curve and micro structure of 3.5 Mg, 3.0 Cu alloy

Figure 8 and Figure 9 illustrate the Stress/Strain relationship and micro structures of $3.5 \mathrm{Mg}, 2.5 \mathrm{Cu}$ alloy and that of $3.5 \mathrm{Mg}, 3.0 \mathrm{Cu}$ alloy. These alloys behaved in a ductile manner with better elongateability properties. This may not be unconnected to the \% wt. of $\mathrm{Cu}$ as they displayed a UTS of $175 \mathrm{~N} / \mathrm{mm}^{2}$ and $280 \mathrm{~N} / \mathrm{mm}^{2}$ respectively. The implication of this result on the tensile strength is that these alloys can find applications in environment where uniaxial tensile strength of less than $280 \mathrm{~N} / \mathrm{mm}^{2}$ is a requirement. The structures of both alloys revealed compaction and isotropic nature of the alloys and aligned closely with the work of [1] with a demonstration of high binding energy between the lattice.

It may be observed also that in both alloys, $\mathrm{Mg}$ was maintained at $3.5 \%$ wt. while $\mathrm{Cu}$ was varied from 2.5 $3.0 \%$ wt. This is an indication that an upward variation in \% wt. of $\mathrm{Cu}$ impacted a corresponding increase in yield strength of almost $105 \mathrm{~N} / \mathrm{mm}^{2}$. The nucleation of cavities, which led to fracture of the specimen, was considered to be related to the prismatic dislocation loops.

The different microstructure as function of the distance from the wall impacted on the mechanical properties of the alloy. It is expected that high properties are associated to a finer microstructure as a result of a reduced tension filed around the eutectic.

\section{Conclusion}

Samples of an experimental X7475 Al alloy was made from constituents drawn from $6 \% \mathrm{Zn}, 2.5 \%-3.5 \% \mathrm{Mg}$, $1.8 \%-3.0 \% \mathrm{Cu}, 0.03 \% \mathrm{Mn}, 0.23 \% \mathrm{Cr}$ and $\mathrm{Al}$ as balance in all cases. The intent was to determine the impact made on the mechanical properties (e.g. yield strength, elongation and micrographic structures) by the variation made to $\mathrm{Mg}$ and $\mathrm{Cu}$. However, $0.1 \mathrm{~g}$ of $\mathrm{S}$ equivalent to $\mathrm{Fe}$ in $\mathrm{Cr}$ and $\mathrm{Mn}$ was added to eradicate $\mathrm{Fe}$. We observed an increase in yield strength with increase in $\mathrm{Mg}$ and decrease with increase in Cu. Ductility and elongation both increased with increase in $\mathrm{Cu}$. The yield strength alternated between $150 \mathrm{~N} / \mathrm{mm}^{2}$ and 384.57 $\mathrm{N} / \mathrm{mm}^{2}$.

Impurities in the form of $\mathrm{K}, \mathrm{Si}$, Ca and $\mathrm{Ti}$ were picked up during the casting process and may likely affect the mechanical properties obtained in this experiment. Also, the presence of Fe was observed to initiate brittleness of the alloy. The tensile strength of the alloy increased with the addition of $\mathrm{Zn}$ and $\mathrm{Mg}$ even as $\mathrm{Cu}$ had positive impact on the elongation of the aluminium alloy. Mechanical properties of $\mathrm{Al}$ alloys depend not only on the content of alloying elements, but also on their relative chemistries with each other and heat treatments.

The alloy of $89.41 \% \mathrm{Al}, 6 \% \mathrm{Zn}, 2.5 \% \mathrm{Mg}, 3.0 \% \mathrm{Cu}$, $0.03 \% \mathrm{Mn}$ and $0.23 \% \mathrm{Cr}$ configuration was recommended for high yield strength applications, while that with $2.5 \%$ $\mathrm{Mg}, 1.8 \% \mathrm{Cu}$ was recommended for high elongation applications. Additional research work is necessary to address constraints of machine availability, appraisal of the impacts of these variations on hardness and purity of alloy constituents.

\section{References}

[1] Al-Rawajfeh, A.E. and Al Qawabah, S.M.A. (2009). Investigation of copper addition on the mechanical properties and corrosion Resistance of commercially pure aluminium. Emirates Journal for Engineering Research, 14 (1), 47-52 (2009).

[2] Aniruddha, M. (2010). Tensile test of Aluminium at high temperature. National Institute of Technology Rourkela769008unpublished. Assessed online at http://ethesis.nitrkl.ac.in/1805/1/final_year_project_report_anirudd hameena.pdf on 22/1/2012.

[3] Bray, J. L. (1947). Non-Ferrous Production Metallurgy (New York: John Wiley \& Sons, 1947), Chapter 4.

[4] Briston, H.F, and Briston, L.C., (2008). Stress and Strain Analysis and Measurement in Polymer Engineering and Viscoelasticity, an introduction. Assessed online at http://www.springer.com/978-0387-73860-4 on 1/2/2012.

[5] Davis, B. and Hryn, J.(2007). Innovative forming and fabrication technologies: new opportunities. Assessed online at http://www.osti.gov/bridge/product.biblio.jsp?osti_id=924692 on $7 / 4 / 2011$.

[6] Davis, J.R. (2004). Tensile Testing, 2nd Edition 05106G Materials Park, Ohio, USA. Assessed online at http://www.asminternational.org/content/ASM/StoreFiles/05106G _Frontmatter.pdf on 5/1/2012.

[7] Dossett, J.L. and Boyer, H.E (2006). Practical heat treating. ASM International. Pp. 17-22.

[8] Hossain A. \& Kurny A. S. W. (2013). Effect of Ageing Temperature on the Mechanical Properties of Al-6Si-0.5Mg Cast Alloys with $\mathrm{Cu}$ Additions Treated by T6 Heat Treatment. Universal Journal of Materials Science 1(1): 1-5.

[9] John, S., Vidosic, J. P., Harold, V. H. and Donald, D. D. (n.d). Strength of Materials (Mechanical properties of materials). Pp 115.

[10] Luebkeman, C. and Peting, D. (2012). Stress-strain curves. Assessed online at

http://en.wikipedia.org/w/index.php?title=Stress\%E2\%80\%93strai ncurve\&oldid=469059832 on 14/1/2012.

[11] Lyle, J.P., Granger, D.A., and Sanders, R.E. (2005). Aluminium Alloys. Assessed online at http://en.wikipedia.org/wiki/ullmann\%27s_encyclopedia_of_indus trial_chemistry/ www.v.engineering.de/pro.of.Al.pdf on 31/03/2011. 
[12] Mohammed, S. (2010). A guide to alloying of non-ferrous metals. Unpublished, paper presented during an in-house seminar at the National Metallurgical Centre, Jos.

[13] Samsudi, S. (n.d). Mechanical Properties and Testing lecture note on Materials Science (SSP 2412). Physics Dept. Faculty of Science, Universiti Teknologi Malaysia.

[14] Sanders R.E. (2001). Technology Innovation in aluminium Products. The Journal of the Minerals, 53(2): 21-25, 2001.
[15] Tapany U. (2007). Aluminium and its alloys, Lecture 2. Suranaree University of Technology May-Aug 2007.

[16] Zhenguo, C. (2010). Superplasticity of coarse grained aluminum alloys. Assessed online at

http://www.materials.manchester.ac.uk/documents/research/epsrc/ latest/Project\%20Number\%203\%20\%20Superplasticity\%20of\%2 0coarse\%20grained\%20aluminium\%20alloys.pdf on 28/10/2010. 